\title{
A Research Algorithm to Sentence the Lots for Costly or Destructive Products in Mixed Quality Characteristics
}

\author{
K. Rebecca Jebaseeli Edna, V. Jemmy Joyce
}

\begin{abstract}
This paper deals with the new operating procedure of Acceptance Sampling Plans for costly or destructive products when the incoming lots have mixed quality characteristics. The Operating Characteristic function and other associated measures of the plan are derived and provided. The procedure is given and designing of sampling plan are indexed through standard quality levels. Tables are constructed for easy selection of the plan.Illustrations are also provided.
\end{abstract}

Keywords - Mixed Sampling, Operating Characteristic function, $A Q L, L Q L$.

\section{INTRODUCTION:}

Mixed Sampling Plan was introduced by Dodge and later Schilling (1967) has given a methodology to determine the Operating characteristics function and its associated measures. Mixed Sampling Plan has two stages. The first stage is considered with variable criteria and the second stage is considered with attribute quality characteristics. In a Mixed Sampling Plans, the second stage of attribute testingbecomes more important to discriminate the lot, if the first stage variable inspection fails to accept the lot. In the second stage, acceptance number of zero plans is more emphasized for practical reason. However the OC curve of acceptance number with zero plans does not discriminate between good and bad lots. Hence Chain Sampling is recommended in the second stage of mixed plans. But Chain sampling plans in the second stage does not guarantee small sample sizes. Therefore Two Sided Completechain sampling plans are recommended in the second stage. The resulting plans yield small samples in both the stages.

Dodge (1955) has designed Chain Sampling Inspection Plan. Clark (1960) has developed OC curves for ChSP - 1 Chain Sampling Plans .David Muse and Robert. (1982) have contributed toan approximate method for evaluatingan mixedsampling plansDevaArul Joyce (2010) have designed selection of Mixed Sampling Plans forSecond Quality Lots. DevaArul S and Edna (2010) developed Dependent Multidimensional Mixed Sampling Plans. Govindaraju (1990) has made, selection of Chsp -1 Chain sampling plans for given AQL and LQL. Govindaraju and Lai (1998) have developed modified chain sampling plans with very small sample sizes.

Revised Manuscript Received on April 12, 2019.

K. Rebecca Jebaseeli Edna, Department of Mathematics, Karunya Institute of Technology and Sciences, (Deemed to be University)Coimbatore, Tamil Nadu, India.

V. Jemmy Joyce, Department of Mathematics, Karunya Institute of Technology and Sciences, (Deemed to be University)Coimbatore, Tamil Nadu, India.

\section{FORMULATION:}

The development of mixed plans and the subsequent discussion are limited only to the upper specification limit. By symmetry a parallel discussion can be made use for lower specification limits. It is suggested that the mixed plans with two chain sampling as attribute plan in the case of single sided specification (U), standard deviation known can be formulated by the four parameters $\mathrm{n}_{1}, \mathrm{n}_{2}$, $\mathrm{k}$ and $\mathrm{i}$.

Where,

$n_{1}=$ First Sample Size

$\mathrm{k}=$ Variable Factor such that a lot is accepted if $\bar{x} \leq U-k \sigma$

$\mathrm{U}=$ Upper Specification Limit.

$n_{2}=$ Second Sample Size.

$\mathrm{N}=$ Lot size.

$\bar{x}=$ Sample Mean

$\sigma=$ Population Standard Deviation.

\section{CONDITIONS FOR APPLICATIONS:}

1. The Production Process should be steady and continuous.

2. Inspection is done due to variable Quality Characteristics in the first stage and Attribute quality characteristics in the second stage.

3. Single sampling inspection in the first stage and Modified chain sampling plans in the second stage.

\section{ALGORITHM FOR SENTENCING A LOT:}

Let the two stages be independent.

Step (1) Determine the four parameters usually with reference to ASN \& OC curves

Step (2) Take a random sample of size $\mathrm{n}_{1}$ from the lot.

Step (3) If the sample average $\bar{x} \leq A=U-k \sigma$, accept the lot.

Step (4) If the sample average $\bar{x}>A$, take a second sample of size $\mathrm{n}_{2}$.

Step (5) Inspect and find the number of defectives (d) in the second sample.

(i) Accept the lot, if $d$ (the observed number of defectives) is zero in the sample ofn ${ }_{2}$ units and reject if $d>1$.

(ii) Accept the lot, if $\mathrm{d}=1$ and if no defectives are found in the immediately preceding ' $i$ ' samples and succeeding ' $j$ ' samples of size $n_{2}$.

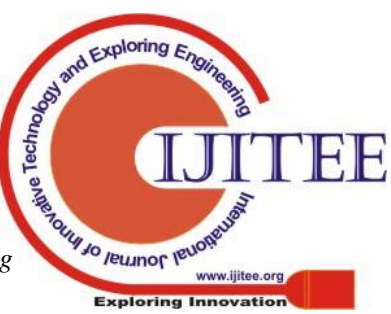




\begin{tabular}{|c|c|c|c|c|c|c|c|c|c|}
\hline \multirow[t]{2}{*}{$p_{1}$} & \multicolumn{5}{|c|}{ Values of $n_{2}$} & \multicolumn{4}{|c|}{ Values of $\mathrm{k}$} \\
\hline & $\mathrm{i}=\mathbf{j}=\mathbf{1}$ & $\mathrm{i}=\mathbf{j}=\mathbf{2}$ & $\mathrm{i}=\mathrm{j}=\mathbf{3}$ & $\mathrm{i}=\mathrm{j}=4$ & $\mathrm{i}=\mathrm{j}=5$ & $n_{1}=5$ & $n_{1}=10$ & $n_{1}=15$ & $n_{1}=20$ \\
\hline .001 & 121 & 98 & 78 & 69 & 63 & 2.8674 & 2.9356 & 2.9657 & 2.9837 \\
\hline .0015 & 80 & 61 & 52 & 46 & 42 & 2.7274 & 2.7956 & 2.8257 & 2.8437 \\
\hline .002 & 60 & 46 & 39 & 35 & 30 & 2.6474 & 2.7156 & 2.7457 & 2.7637 \\
\hline .0025 & 48 & 36 & 31 & 28 & 25 & 2.5774 & 2.6456 & 2.6757 & 2.6937 \\
\hline .003 & 40 & 30 & 26 & 23 & 21 & 2.5174 & 2.5856 & 2.6157 & 2.6337 \\
\hline .0035 & 34 & 26 & 22 & 20 & 18 & 2.4674 & 2.5356 & 2.5657 & 2.5837 \\
\hline .004 & 30 & 23 & 19 & 17 & 15 & 2.4174 & 2.4856 & 2.5157 & 2.5337 \\
\hline .0045 & 26 & 20 & 17 & 14 & 13 & 2.3774 & 2.4456 & 2.4757 & 2.4937 \\
\hline .005 & 24 & 18 & 15 & 13 & 12 & 2.3374 & 2.4056 & 2.4357 & 2.4537 \\
\hline
\end{tabular}

\section{MEASURES OF INDEPENDENT PLAN:}

I. Probability of Acceptance

$$
\begin{gathered}
P_{a}(p)=P_{n_{1}}(\bar{x} \leq A)+P_{n_{1}}(\bar{x}>A) P_{0}^{i} P_{1} P_{0}^{j} \\
P_{0}=e^{-n_{2} p} \text { and } P_{1}=n_{2} p e^{-n_{2} p} \\
P_{a}(p)=e^{-n p}\left\{1+n p e^{-2 i n p}\right\}, \text { if } i=j
\end{gathered}
$$

II. Average sample number:

$$
\mathrm{ASN}=n_{1}+n_{2} P(\bar{x}>A)
$$

III. Average Total Inspection

$$
\mathrm{ATI}=\mathrm{ASN}+\left(\mathrm{N}-n_{1}-n_{2}\right)\left(1-P_{a}(\mathrm{p})\right)
$$

IV. Average Outgoing Quality:

$$
\mathrm{AOQ}=\mathrm{p} . \mathrm{Pa}(\mathrm{p}), \text { if } \mathrm{n} \text { is large }
$$

\section{DESIGNING MIXED SAMPLING PLANS INDEXED THROUGH AQL}

Designing the mixed sampling plan with variable Single sampling plans in the first stage and two-sided complete chain sampling plan as attribute plan in the second stage, when $\left(p_{1}, \beta_{1}\right), i$ and the first sample size $n_{1}$ are known. Assume that probability of acceptance assigned to the attribute plan associated with the second stage sample as the mixed plans are independent

1. Split the probability of acceptance that will be assigned to the first stage. Let it be $\beta_{1}$ '.

2. Decide the sample size $\mathrm{n}_{1}$, which is to be used.

3. Calculate the acceptance limit as

$$
A=U-\left[Z\left(p_{1}\right)+\frac{Z\left(\beta_{1}{ }^{1}\right)}{\sqrt{n_{1}}}\right] \sigma
$$

4. Now determine $\beta_{1}$, the probability of acceptance assigned to the attribute plan associated with the second stage sample as,

$$
\beta_{1}^{\prime \prime}=\frac{\beta_{1}-\beta_{1}^{\prime}}{1-\beta_{1}^{\prime}}
$$

5. Determine the appropriate second stage sample of size $\mathrm{n}_{2}$ for the givenindex i from the relation.

$$
e^{-n_{2} p}\left\{1+n_{2} p e^{-2 i n_{2} p}\right\}=\beta_{1} \text {, if } i=j
$$

The above equations cannot be solved easily. Hence the solutions are obtained by using an iterative procedure. A computer program is written to solve the equations and to construct the tables. Using the above procedure tables are constructed to facilitate easy selection of mixed acceptance sampling plan with modified chain sampling as attribute plan.

Table :1 Shows the values of the first stage variable criteria ' $k$ ' and the second stage sample size $\mathrm{n}_{2}$ for the known AQL (Using two-sided chain sampling plan as attribute plan in the second stage). $\beta_{1}=0.99, \beta_{1}{ }^{\prime}=0.70$

\section{Illustration : 1}

Suppose a production process turns out $4 \%$ defective, obtain the corresponding mixed sampling plan with twosided chain sampling as attribute plan with Probability of acceptance as $95 \%$ and the past lot index $\mathrm{i}=\mathrm{j}=4$

\section{Solution:}

Let the first stage sample size ben $n_{1}=15$.It is given that the probability of acceptance is $95 \%$. Let us bifurcate the $1^{\text {st }}$ stage probability of acceptance. $\beta_{1}^{\prime}=0.70$. Then the second stage probability of acceptance will be $\beta_{1}=$ 0.97. If the first stage sample size $\mathrm{n}_{1}=15$ then from table $1, \mathrm{n}_{2}=17$

Hence, the parameters of mixed sampling plan with two-sided chain sampling are $\mathrm{n}_{1}=15, \mathrm{n}_{2}=17, \mathrm{i}=\mathrm{j}=4$ and $\mathrm{k}=2.5157$.

\section{Algorithm for sentencing a lot}

Step (i) Take a random sample of size $n_{1}=15$ from the lot.

Step (iii) If the sample average $\bar{x} \leq A=U-2.5157 \sigma$, accept the lot.

Step (iv) If the sample average $\bar{x}>\mathrm{A}=U-2.5157 \sigma$ take a second sample of size $\mathrm{n}_{2}=17$

Step (v) Inspect and find the number of defectives (d) in the second sample.

(1) Accept the lot if $d$ (the observed number of defectives) is zero in the sample of $n_{2}=17$ units and reject if $d>1$. 
(2) Accept the lot if $d=1$ and if no defectives are found in the immediately preceding $i=4$ samples and succeedingj $=4$ samples of size

\section{DESIGNING MIXED SAMPLING PLANINDEXED THROUGH LQL\& RESULTS}

Designing the mixed sampling plan with variable Single sampling plans in the first stage the two-sided complete chain sampling plan as attribute plan in the second stage, when $\left(\mathrm{p}_{2}, \beta_{2}\right)$, and the first sample size $\mathrm{n}_{1}$ are known. Let the probability of acceptance assigned to the attribute plan associated with the second stage sample as the mixed plans are independent

1. Split the probability of acceptance that will be assigned to the first stage. Let it be $\beta_{2}$.

2. Decide the sample size $\mathrm{n}_{1}$, which is to be used.

3. Calculate the acceptance limit as

$$
A=U-\left[Z\left(p_{2}\right)+\frac{Z\left(\beta_{2}^{\prime}\right)}{\sqrt{n_{1}}}\right] \sigma
$$

4. Now determine $\beta 2$ " the probability of acceptance assigned to the attribute plan associated with the second stage sample as,

$$
\beta_{2}{ }^{\prime \prime}=\frac{\beta_{2}-\beta_{2}^{\prime}}{1-\beta_{2}^{\prime}}
$$

5. Determine the appropriate second stage sample of size $\mathrm{n}_{2}$ for the known index $\mathrm{i}$ from the relation.

$$
e^{-n_{2} p}\left\{1+n_{2} p e^{-2 i n_{2} p}\right\}=\beta_{2}, \text { if } i=j
$$

Theaboveequationscannotbesolved easily.Hence, thesolutionsare obtained by using an iterative procedure. A computer program is written to solvethe equations and

\begin{tabular}{|c|c|c|c|c|c|c|c|c|c|}
\hline \multirow[t]{2}{*}{$p_{2}$} & \multicolumn{5}{|c|}{ Values of $n_{2}$} & \multicolumn{4}{|c|}{ Values of $\mathrm{k}$} \\
\hline & $\mathrm{i}=\mathbf{j}=\mathbf{1}$ & $\mathbf{i}=\mathbf{j}=\mathbf{2}$ & $\mathbf{i}=\mathbf{j}=\mathbf{3}$ & $\mathrm{i}=\mathrm{j}=4$ & $\mathrm{i}=\mathrm{j}=5$ & $n_{1}=5$ & $\mathrm{n}_{1}=10$ & $\mathrm{n}_{1}=15$ & $\mathrm{n}_{1}=\mathbf{2 0}$ \\
\hline .01 & $>300$ & $>300$ & $>300$ & $>300$ & $>300$ & 4.2225 & 3.8937 & 3.7481 & 3.6613 \\
\hline .015 & $>300$ & $>300$ & $>300$ & $>300$ & $>300$ & 4.0825 & 3.7537 & 3.6081 & 3.5213 \\
\hline .02 & 276 & 276 & 276 & 276 & 276 & 4.0025 & 3.6737 & 3.5281 & 3.4413 \\
\hline .025 & 220 & 220 & 220 & 220 & 220 & 3.9325 & 3.6037 & 3.4581 & 3.3513 \\
\hline .03 & 184 & 184 & 184 & 184 & 184 & 3.8725 & 3.5437 & 3.3981 & 3.3113 \\
\hline .035 & 157 & 157 & 157 & 157 & 157 & 3.8225 & 3.4937 & 3.3481 & 3.2613 \\
\hline .04 & 138 & 138 & 138 & 138 & 138 & 3.7725 & 3.4437 & 3.2981 & 3.2113 \\
\hline .045 & 122 & 122 & 122 & 122 & 122 & 3.7325 & 3.4037 & 3.2581 & 3.1713 \\
\hline .05 & 110 & 110 & 110 & 110 & 110 & 3.6925 & 3.3637 & 3.2181 & 3.1313 \\
\hline
\end{tabular}
tables are constructed to facilitate easy application in industries.
Table :2 Values of the first stage variable criteria ' $\mathrm{k}$ ' and the second stage sample size $\mathrm{n}_{2}$ for the known LQL (Using two-sided chain sampling plan as attribute plan in the second stage). $\beta_{2}=0.01, \beta_{2}{ }^{\prime}=0.006$

\section{Illustration : 2}

If $\mathrm{n}_{1}=10, \mathrm{p}_{2}=.05$ is a fraction defective corresponds to LQL and attribute index $\mathrm{i}=\mathrm{j}=3$, obtain the corresponding mixed sampling plan.

Solution :Let $\beta_{2}{ }^{\prime}=.006$ be the probability of acceptance in the $1^{\text {st }}$ stage and assume $\mathrm{n}_{1}=10$

From the table2, $\mathrm{n}_{2}=110$. Hence the parameters are $\mathrm{n}_{1}=10, \mathrm{n}_{2}=110, \mathrm{i}=\mathrm{j}=3$ and $\mathrm{k}=3.3637$

\section{Algorithm for sentencing a lot}

Step (i) Take a random sample of size $n_{1}=10$ from the lot.

Step (iii) If the sample average $\bar{x} \leq A=U-3.3637 \sigma$, accept the lot.

Step (iv) If the sample average $\bar{x}>\mathrm{A}=U-3.3637 \sigma$ take a second sample of size $\mathrm{n}_{2}=110$

Step (v) Inspect and find the number of defectives (d) in the second sample..

(1) Accept the lot if $d$ (the observed number of defectives) is zero in the sample ofn $n_{2}=110$ units and reject if $\mathrm{d}>1$.
(2) Accept the lot if $d=1$ and if no defectives are found in the immediately preceding $i=3$ samples and succeeding $=3$ samples of $\operatorname{sizen}_{2}=110$

\section{CONCLUSION:}

Hence in this paper Mixed Sampling Plan with Two Sided Complete Chain Sampling as attribute planis developed by considering the results of past as well as future lots if the current sample does not leadto acceptance. There are possibilities in many production industries for consideringpast, current andfuture samples. Hence this proposed plan can be used to inspect very costly or destructive items..Tables are constructed forthe easy selection of the plan.

\section{REFERENCES:}

1. CLARK, C.R. (1960). "OC curves for ChSP - 1 Chain Sampling Plans”. Industri Quality Control. Vol.17,No.4, pp.10 -12.

2. DAVID MUSE, H. and ROBERT, S.E. (1982). “An approximate method for evaluatingan mixedsampling plans”. Technometrics. Vol.24, pp.207-211. 
3. DEVAARUL, S.andJOYCE, V. (2010). "Selection of Mixed Sampling Plans forSecond Quality Lots".Economic Quality Control, Germany. Vol. 25,pp. $21-42$.

4. DEVAARUL $S$ and REBECCA JEBASEELI EDNA K (2010) Dependent Multi-dimensional Mixed Sampling Plans International Journal of Applied Mathematics and Computation 8(S10):28-38.

5. DODGE, H.F. (1955). "Chain Sampling Inspection Plan”. Industrial Quality Control.Vol.11, No.4,pp.1013.

6. GOVINDARAJU, K. (1990)."Selection of Chsp -1 Chain Sampling Plans for given AQL and LQL".Communication in Statistics - Theory and Methods. Vol.19,No.6, pp.2179-2190.

7. GOVINDARAJU, K. and LAI, C.D. (1998). "A modified Chsp-1 Chain Sampling Plan, MChsp-1, with very Small Sample Sizes". American Journal of Mathematical and ManagementSciences. Vol. 18, No. 3\&4, pp.343-358. 